\title{
Octadecadienoic Acid
}

National Cancer Institute

\section{Source}

National Cancer Institute. Octadecadienoic Acid. NCI Thesaurus. Code C68398.

A polyunsaturated long-chain fatty acid with an 18-carbon backbone and exactly 2 double bonds. There are numerous isomers and stereoisomers that can be called by this name. 